\title{
Clinical and technical aspects regarding the aesthetic individualization of the bases of complete dentures
}

\author{
Aspecte clinice și tehnice privind individualizarea estetică a bazelor protezelor totale
}

\author{
Marina Meleșcanu Imre1, Simona Crivățu², Mihaela Pantea³, \\ Alexandra Totan", Ana Maria Cristina Țâncu' ${ }^{1}$ \\ ${ }^{1}$ Disciplina Protezare Totală, Facultatea de Medicină Dentară, \\ Universitatea de Medicină şi Farmacie „Carol Davila“, București \\ 2 Practică Privată, București \\ ${ }^{3}$ Disciplina Protetică Dentară Fixă și Ocluzologie, Facultatea de Medicină Dentară, \\ Universitatea de Medicină şi Farmacie „Carol Davila“, București \\ ${ }^{4}$ Disciplina Biochimie, Facultatea de Medicină Dentară, \\ Universitatea de Medicină şi Farmacie „Carol Davila“, București
}

\begin{abstract}
Objective. Highlight of the importance of the aesthetic individualization techniques of the bases of the complete dentures in accordance with the increased aesthetic expectations of the seniors and with the current standards of full edentulism prosthetic techniques.

Material and method. Description and analysis of the facial parameters and the morphological characteristics of the fixed gingiva of the vestibular slope of the edentulous ridge in order to record the elements of aesthetic individualization. Presentation of the laboratory technique and of the materials used.

Results and discussions. Clinical and technical evaluation of the method of aesthetic individualization of the acrylic bases of the complete denture in the context of the new trends in dentistry in the prosthetic field.

Conclusions. The need for the dentist to be familiar with the individual characteristic elements in the rehabilitation of the physiognomy in full edentulous patient and the training of the dental technicians on the materials and the laboratory techniques used in the individualization of the bases of complete denture.
\end{abstract}

Keywords: full edentulism, morphological characteristics, individualization of the denture basis

\section{REZUMAT}

Obiectiv. Demonstrarea importanței tehnicilor de individualizare estetică a bazelor protezelor totale în concordanță cu creșterea așteptărilor estetice ale seniorilor și cu standardele actuale ale protezării edentației totale.

Material și metodă. Descrierea și analiza parametrilor faciali și a caracteristicilor morfologice ale mucoasei fixe a versantului vestibular al crestei edentate în vederea înregistrării elementelor de individualizare estetică. Prezentarea tehnicii de laborator și a materialele folosite.

Rezultate şi discuţii. Evaluarea clinică și tehnică a metodei de individualizare estetică a bazelor acrilice ale protezelor totale, în contextul noilor tendințe ale stomatologiei în domeniul protetic.

Concluzii. Necesitatea pentru medicul stomatolog de cunoastere a elementelor caracteristice individuale în reabilitarea fizionomiei în edentația totală și instruirea tehnicienilor dentari asupra materialelor și tehnicilor de laborator folosite în individualizarea bazelor protezelor totale.

Cuvinte cheie: edentație totală, caracteristici morfologice, individualizarea bazei protezei 


\section{INTRODUCERE}

Reabilitarea morfo-funcțională a edentatului total reprezintă o adevărată provocare atât pentru pentru medicul stomatolog, cât și pentru laboratorul de tehnică dentară. Numărul pacienților edentați total este în continuă creștere, rezultând astfel interesul actual al abordării unei astfel de tematici.

Având în vedere cerinţele estetice crescute ale seniorilor în concordanță cu creșterea perioadei de viață activă și cu standardele actuale ale calităţii vieții, reabilitarea morfo-funcțională a edentației totale, în special în cazul soluțiilor alternative de protezare pe implanturi, trebuie să includă toate elementele de individualizare necesare reabilitării aspectului de edentat (1).

Fără îndoială, dintre acestea face parte și individualizarea bazei protezei - în acord cu caracteristicile pacientului (2). Acest aspect important este mai puţin tratat în literatura de specialitate, dar și mai puțin cunoscut în practica clinică totale.De multe ori, atunci când vorbim despre estetică, ne gândim la aspecte legate de dinţi și caracteristicile acestora (montare, formă, culoare etc.), iar în ceea ce privește baza protezei și aspectul său se folosesc soluții standard, fără caracteristicile individuale ale pacientului. Astăzi, este documentat în literatura de specialitate rolul lui pink esthetic versus white esthetic sau, mai bine spus, complementaritatea celor două aspecte care vor defini rezultatul estetic final $(3,4)$.

Așa cum au enunțat Frush \& Fisher, mediul înconjurător al dintelui este la fel de important ca și dintele în sine.

Realizarea unei estetici adecvate a bazei protezei depinde de trei factori cheie: analiza caracteristicilor gingiei, materialele folosite și etapele tehnice de laborator.

Scopul acestui articol este de a oferi o abordare sistematică a analizei și reproducerii caracteristicilor gingivale la purtătorii de proteze totale.

\section{MATERIAL ŞI METODĂ}

Analiza caracteristicilor gingivale presupune evaluarea a trei parametri: vizibilitatea festonului gingival în surâs, caracteristicile pigmentare și cele morfologice ale gingiei, vizibilitatea festonului gingival.
Exemplificăm prin cazul pacientului F.N, în vârstă de 82 de ani, edentat total maxilar protezat printr-o proteză totală convenţională. Se remarcă o linie a surâsului înaltă cu dezvelirea a $4 \mathrm{~mm}$ din baza protezei - aspect inestetic (Fig. 1, Fig. 2, Fig. 3).

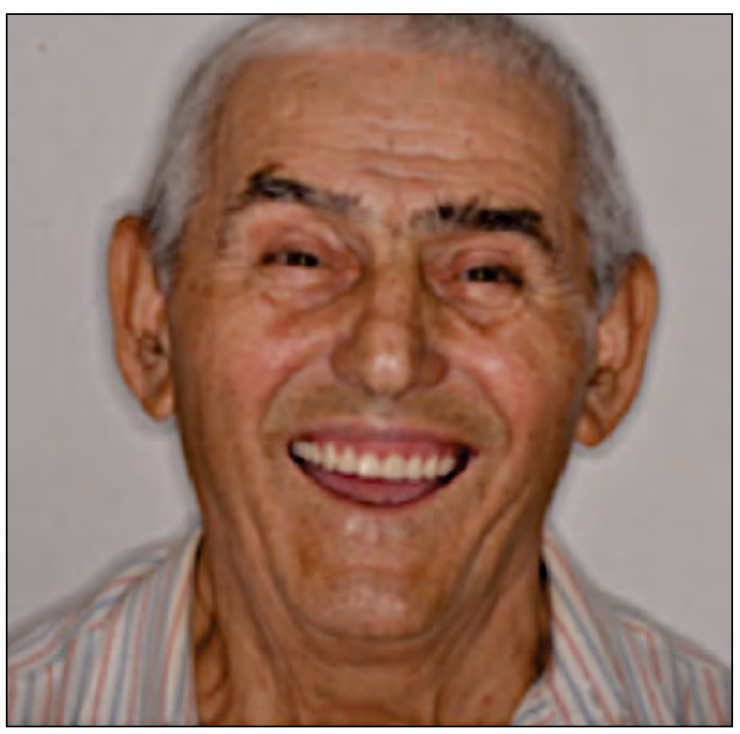

FIGURA 1. Vizibilitate în surâs

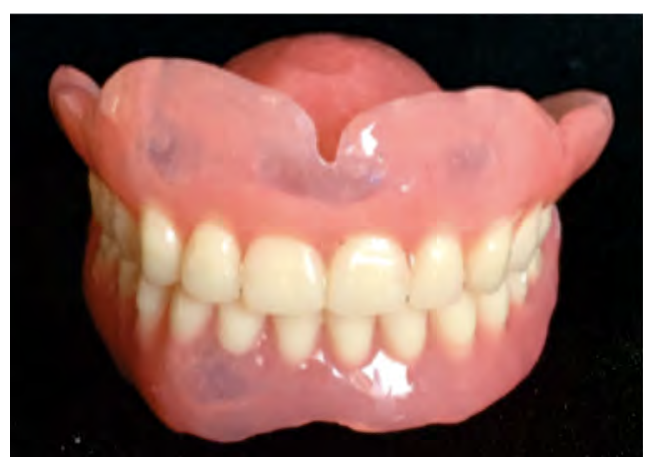

FIGURA 2. Aspect extraoral

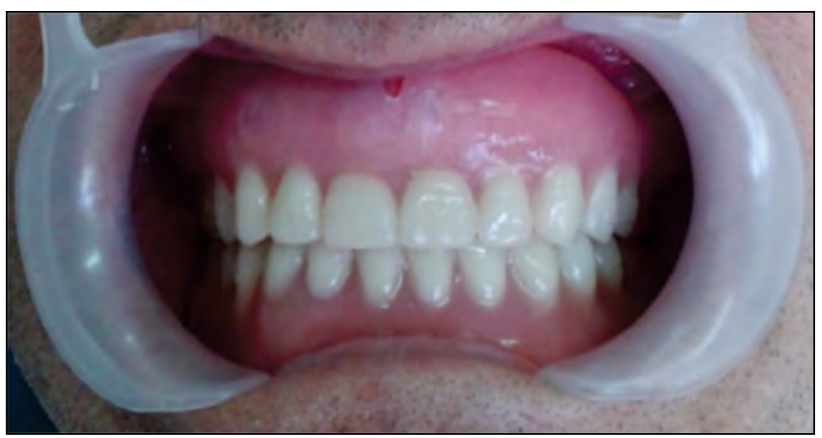

FIGURA 3. Aspect intraoral

Evaluarea caracteristicilor pigmentare. Pacientul F.N., de sex masculin, este de tip caucazian și prezintă o colorație roz pal, cu zone de intensificare pigmentare de culoare roz mai intens ale mucoasei crestei edentate maxilare (Fig. 4). 


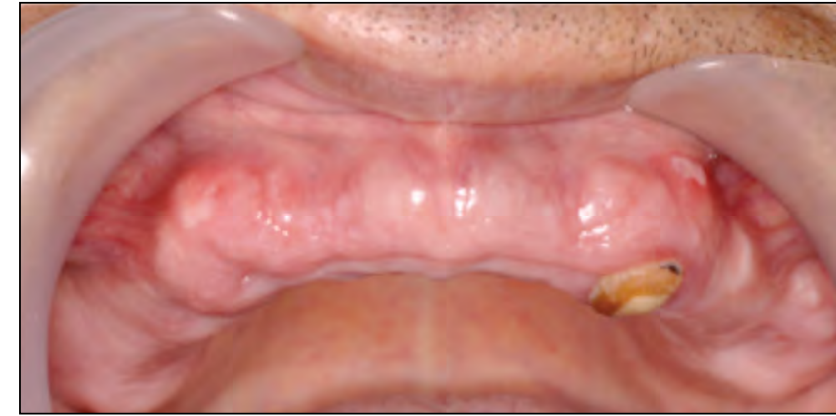

FIGURA 4. Aspectul mucoasei

Evaluarea caracteristicilor morfologice. Examinarea endobucală a substratului mucos relevă o mucoasă fixă subțire aderentă de periost, sensibilă la palpare, aspect de ,coajă de portocală“.

Materiale. Pentru individualizarea estetică a bazei protezei, se pot folosi rășini acrilice de tip PMMA sau materiale compozite.

Etapele de lucru au constatat, ca prim pas, în subțierea bazei protezei existente și în modelarea corectă a bazei protezei în zona vestibulară și a festonului gingival (Fig. 5).
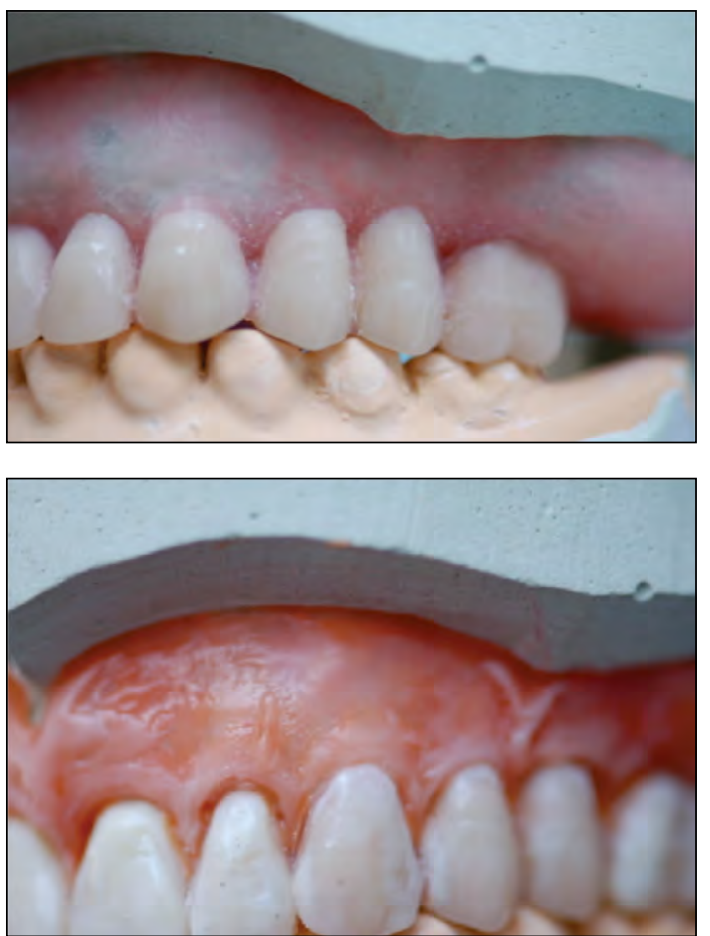

FIGURA 5. Modelarea versantului vestibular al bazei protezei

Aplicarea gelului înainte de polimerizare prin modelare este conformă cu caracteristicile morfologice ale substratului mucos (Fig. 6).

Are loc aplicarea individualizată a culorilor din baza protezei și modelarea festonului gingival. Etapele de laborator se încheie cu prelucrarea bazei

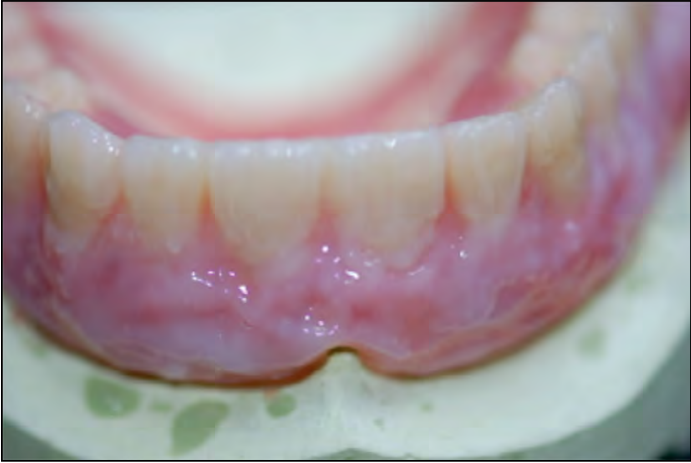

FIGURA 6. Aplicarea gelului prin modelare

protezei prin lustruire cu paste abrazive, urmată de lustruire cu pufuri de căprioară și pufuri din bumbac.

\section{REZULTATE ŞI DISCUȚII}

Individualizarea estetică a bazei protezei - conform caracteristicilor faciale, ale coloraţiei pigmentare a mucoasei și ale aspectelor morfologice ale acesteia - oferă rezultate protetice la cele mai înalte standarde estetice (Fig. 7).
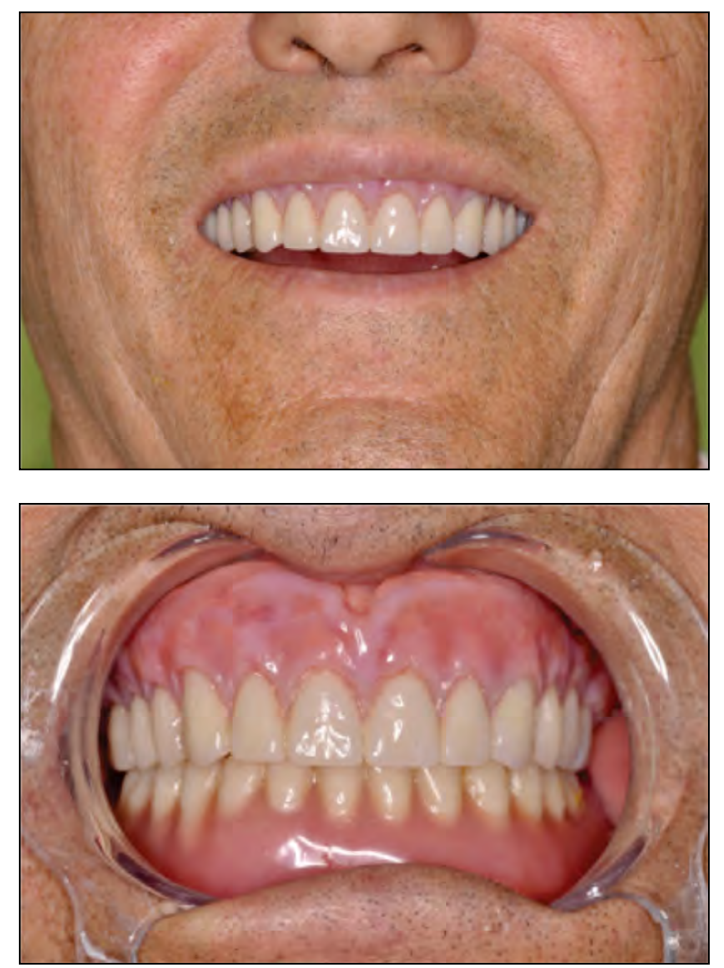

FIGURA 7. Rezultatul final

În prezent, este considerată acceptabilă din punct de vedere estetic o vizibilitate de 2-3 mm a festonului gingival. O linie a surâsului joasă dezvăluie numai marginile incizale, o linie mijlocie afișează dinții integral, iar o linie înaltă implică afișarea gingivală. Gradul de vizibilitate scade 
semnificativ cu vârsta. Astfel, în cazul edentatului total cu un grad mare de expunere a festonului gingival, medicul stomatolog poate alege una dintre cele 2 variante: montarea unor dinţi artificiali mai lungi, cu repercusiuni estetice și funcționale, sau varianta optimă - individualizarea estetică a bazei protezei.

În privința evaluării caracteristicilor pigmentare ale mucoasei, se procedează conform lui Dummet $(5,6)$, care a descris caracteristicile coloristice ale mucoasei bucale: „Culoarea gingiei sănătoase variază de la un roz pal la un violet albăstrui“. La caucazieni, mucoasa fixă sănătoasă prezintă variații ușoare în jurul nuanțelor de roz. La afro-americani sau cu tipuri de piele mai închisă, apar zone de pigmentare brune de diverse intensități; acestea sunt cauzate de melanocitele din substratul gingival scuamos stratificat (7).

Așa cum gradul de vizibilitate a dinților depinde de sex, așa și caracteristicile morfologice gingivale depind și de sex. În $40 \%$ dintre cazuri, mucoasa fixă prezintă denivelări pe suprafață, denumit un ,aspect de coajă de portocală“", care este asociat cu dinții pătrați și mucoasa groasă, albicioasă. Regăsim această suprafaţă în aproximativ 2/3 dintre pacienții de sex masculin. Pacientele prezintă un aspect mai neted al mucoasei fixe, asociat cu dinți mai înguști (8).

Rășinile termopolimerizabile folosite pentru confecționarea bazelor protezelor totale sunt în general roz, variind de la roz pal la roz închis, în funcție de producător. Mai există și rășini a căror textură cuprinde vinișoare mai intens colorate. Totuşi, aceste tonuri și texturi satisfac doar parțial cerințele estetice. Pulberile PMMA dezvoltate pentru individualizarea bazelor protezelor totale prezintă un spectru mult mai larg de tonuri, de culori, variate de la alb până la negru. Aceste pulberi pot fi amestecate direct în rășina pentru turnarea bazei

\section{BIBLIOGRAFIE}

1. Van der Geld $P$, Oosterveld $P$, Van Heck $G$ et al. Smile attractiveness. Self-perception and influence on personality. Angle Orthod 2007; 77:759-765.

2. Berteretche MV, Hue O, The Esthetics of Artificial Gingiva and Complete dentures. The American Journal of Esthetic Dentistry 2012; 2:21-31.

3. Kapagiannidis D, Kontonasaki E, Bikas P, Koidis P. Teeth and gingival display in the premolar area during smiling in relation to gender and age. J Oral Rehabil 2005;32:830-837.

4. Fradeani M. Esthetic Rehabilitation in Fixed Prosthodontics.Volume I: Esthetic Analysis: A Systematic Approach to Prosthetic Treatment. Chicago: Quintessence, 2004.

5. Dummett CO. Oral pigmentation. J Periodontol 1960; 31:356-360. protezei sau pot fi aplicate înainte de ambalare așa cum am arătat $(9,10)$.

Cercetări recente au dus și la dezvoltarea unor răşini compozite fotopolimerizabile care pot fi aplicate pe baza protezei la gata în vederea individualizării estetice. Acestea au o varietate mare de nuanțe şi texturi, aspect care facilitează tehnica de laborator.

\section{CONCLUZII}

Reușita tratamentului și acceptarea de către pacient a protezării sunt dezideratele fiecărui practician, de aceea, este important ca integrarea bio-funcțională a protezării să țină cont de cât mai multe aspecte individuale ale pacientului.

Aspectul dinților și caracteristicile acestora reprezintă doar $50 \%$ din rezultatul estetic în protezarea totală, baza protezei trebuie să fie individualizată în funcție de caracteristicile pacientului - în special la pacienții cu buza superioară scurtă și linia surâsului înaltă. Materialele de laborator moderne permit individualizarea bazei protezei în funcție de caracteristicile pacientului. Individualizarea unei lucrări protetice presupune ca medicul stomatolog să facă o evaluare estetică amănunțită, care să includă și evaluarea caracteristicilor morfologice ale mucoasei. Tehnicianul de laborator trebuie să fie pregătit profesional prin cursuri de specializare asupra noilor tehnici și materiale de individualizare - necesitatea instruirii acestora. Costurile ridicate și timpii de lucru crescuți atât pentru medic, cât și pentru technician justifică individualizarea bazei protezei în protezarea convențională a edentației totale la pacienții cu cerințe estetice crescute, cei cu carateristici funcționale specifice, iar în supraprotezarea mobilă a edentației totale pe implanturi - în toate cazurile.
6. De Krom C. The oral pigmentation. Int J Prosthodont 2005;18 66-70.

7. Powers JM, Capp JA, Koran A. Color of gingival tissues of blacks and whites. J Dent Res 1977; 56:112-116.

8. De Rouck T, Eghbali R, Collys K, De Bruyn H, Cosyn J. The gingival biotype revisited: Transparency of the periodontal probe through the gingival margin as a method to discriminate thin from thick gingiva. J Clin Periodontol 2009; 36: 428-433.

9. Bayindir YZ, Gozalo-Diaz DJ, Wee AG. Coverage error of gingival shade guide systems in measuring color of attached anterior gingiva. J Prosthet Dent 2009; 101:46-53.

10. Schnitzer S, Türp JC, Heydecke G. Color distribution and visual color assessment of human gingiva and mucosa: A systematic review of the literature. Int J Prosthodont 2004; 17:327-332. 